\title{
A case of rupture of right coronary sinus of Valsalva aneurysm after aortic root replacement due to Stanford type A aortic dissection 15 years ago
}

\author{
Satoshi Koto ${ }^{1} \cdot$ Koichiro Imai $^{1} \cdot$ Ryotaro Yamada $^{1} \cdot$ Teruyoshi Kume $^{1} \cdot$ Yoji Neishi $^{1}$. Shiro Uemura ${ }^{1}$
}

Received: 10 June 2020 / Revised: 24 November 2020 / Accepted: 25 November 2020 / Published online: 3 January 2021

(c) The Author(s) 2021

\section{Case report}

A 70-year-old Japanese man presented with symptom of a dyspnea and diagnosed as rupture of right coronary of sinus of Valsalva aneurysm. He had a history of ascending aortic replacement because of Stanford type A aortic dissection 15 years ago. Cardiovascular examination revealed a grade IV/VI continuous cardiac murmur at the right second intercostal space. Transthoracic echocardiography (TTE) revealed shunt through from right coronary sinus of Valsalva aneurysm to right ventricle detected by color Doppler (Fig. 1a) Two- and three-dimensional transesophageal echocardiography (3DTEE) revealed a ruptured aneurysm of the right coronary sinus of Valsalva causing a large leftto-right shunt through into the right ventricle (Fig. 1b) and defect in right coronary sinus of Valsalva during cardiac cycle (Fig. 1c, d). We decided to perform re-ascending aorta replacement with aortic valve replacement. A ruptured coronary aneurysm was observed in the right sinus of Valsalva. The rupture site was accompanied by the destruction of the wall structure (Fig. 1e).
Photomicrograph showing the inner wall of the excised artificial blood vessel. Fibrous capsule appears (black arrow) and fibrin deposition is also observed (white arrow) (hematoxylin and eosin stain, original magnification $3 \times 20 \times 2$ ) (Fig. 1f).

We experienced a case of ruptured sinus of Valsalva aneurysm after ascending aortic replacement for Stanford type A dissection 15 years ago. In this case, gelatin-resorcin-formalin (GRF) glue was used for ascending aortic replacement. The surgical performance of acute aortic dissection had greatly improved by the appearance of GRF glue since 1980. However, stump-plasty using GRF glue has been reported to cause postoperative anastomotic complications in $5-20 \%[1,2]$. Pathological examination showed fragility of the aorta media and coagulation necrosis due to formalininduced tissue injury [3]. Although GRF glue is rarely used, it had been used in many cases previously. Therefore, it is necessary to observe the occurrence of anatomic complications carefully over the long term.

Koichiro Imai

kichiro@med.kawasaki-m.ac.jp

1 Department of Cardiology, Kawasaki Medical School, 577 Matsushima, Kurashiki 701-0192, Japan 


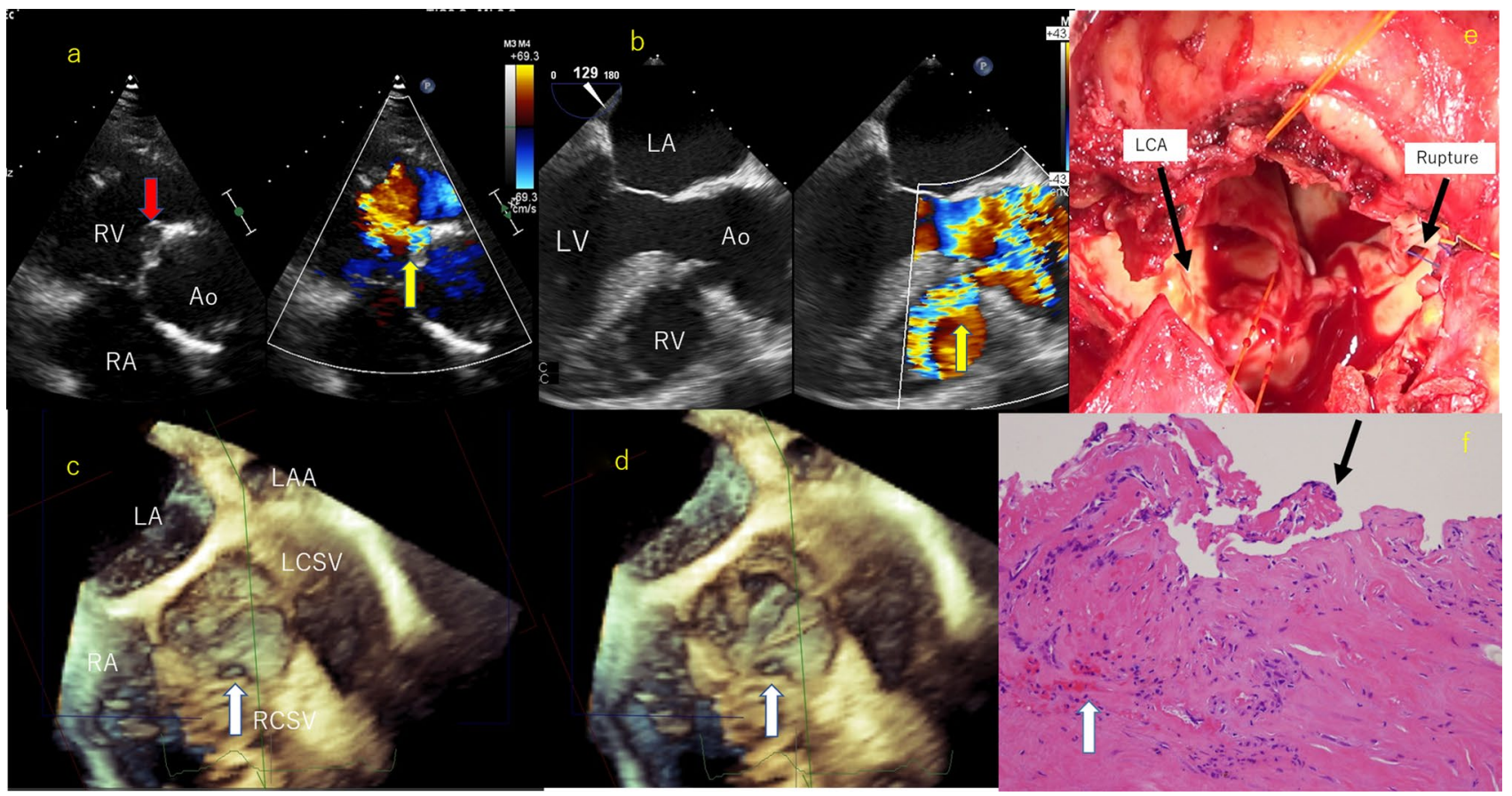

Fig. 1 HYPERLINK "sps:id::fig1|llocator::gr1|lMediaObject::0"a Transthoracic echocardiograph by color Doppler shows right coronary sinus of Valsalva aneurysm (red arrow) and shunt through from right coronary sinus of Valsalva to right ventricle (yellow arrow). $R A$ right atrium, $R V$ right ventricle, $A o$ aorta. b Transesophageal echocardiography by color Doppler shows shunt through from right coronary sinus of Valsalva to right ventricle (yellow arrow). LA left atrium, $L V$ left ventricle, $R V$ right ventricle, $A o$ aorta. c Three-dimensional transesophageal echocardiography detect defect in right coronary sinus of Valsalva (white arrow) in diastole. $L A$ left atrium, $R A$ right

\section{Compliance with ethical standards}

Conflict of interest Satoshi Koto, Koichiro Imai, Ryotaro Yamada, Teruyoshi Kume, Yoji Neishi and Shiro Uemura declare that they have no conflict of interest.

Human rights statements and informed consent All procedures followed were in accordance with the ethical standards of the responsible committee on human experimentation (institutional and national) and with the Helsinki Declaration of 1964 and later revisions. Informed consent was obtained from all patients for being included in the study.

Open Access This article is licensed under a Creative Commons Attribution 4.0 International License, which permits use, sharing, adaptation, distribution and reproduction in any medium or format, as long as you give appropriate credit to the original author(s) and the source, provide a link to the Creative Commons licence, and indicate if changes were made. The images or other third party material in this article are included in the article's Creative Commons licence, unless indicated otherwise in a credit line to the material. If material is not included in the article's Creative Commons licence and your intended use is not permitted by statutory regulation or exceeds the permitted use, you will need to obtain permission directly from the copyright holder. To view a copy of this licence, visit http://creativecommons.org/licenses/by/4.0/. atrium, $L C S V$ left coronary sinus of Valsalva, $R C S V$ right coronary sinus of Valsalva, LAA left atrial appendage. d Three-dimensional transesophageal echocardiography detect defect in right coronary sinus of Valsalva (white arrow) in systole. e Operative findings: view from the left ventricle side. Rupture of right coronary sinus of Valsalva. f Photomicrograph showing the inner wall of the excised artificial blood vessel. Fibrous capsule appears (black arrow) and fibrin deposition is also observed (white arrow) (hematoxylin and eosin stain, original magnification $3 \times 20 \times 2$ )

\section{Reference}

1. Hata M, Shiono M, Sezai A, et al. Type A acute aortic dissection: immediate and mid-term results of emergency aortic replacement with the aid of gelatin resorcin formalin glue. Ann Thorac Surg. 2004;78:853-7.

2. Izutani H, Shibukawa T, Kawamoto J, et al. Devastating late complication for repair of type A acute aortic dissection with usage of gelatin-resorcinol-formalin glue. Int Cardiovasc Surg. 2007;6:240-2.

3. Kazui T, Washiyama N, Bashar AH, et al. Role of biologic glue repair of proximal aortic dissection in the development of early and midterm redissection of the aortic root. Ann Thorac Surg. 2001;72:509-14.

Publisher's Note Springer Nature remains neutral with regard to jurisdictional claims in published maps and institutional affiliations. 